УДК 004.891:629.735

${ }^{[0000-0002-6204-0708]}$ Т. О. Прокопенко ${ }^{1}$, д.т.н., професор,

${ }^{[0000-0003-1566-9260]}$ М. О. Можаєв ${ }^{2}$, к.m.н., ${ }^{[0000-0003-4389-1088]}$ С. В. Рудницький ${ }^{1}$, к. ${ }^{[0000-0001-6384-0523]}$ Ю. В. Рудницька ${ }^{1}$

${ }^{1}$ Черкаський державний технологічний університет

б-р Шевченка, 460, м. Черкаси, 18006, Україна

${ }^{2}$ Харківський науково-дослідний інститут судових експертиз ім. засл. проф. М. С. Бокаріуса вул. Золочівська, 8а, м. Харків, Україна

\title{
ПРОГРАМУВАННЯ РЕЖИМУ НЕНАВАНТАЖЕНОГО РЕЗЕРВУВАННЯ У КОМП'ЮТЕРНИХ СИСТЕМАХ КРИТИЧНОГО ЗАСТОСУВАННЯ
}

Особливого значення на сьогодні в задачах підвищення ефективності використання каналів комп'ютерних систем критичного застосування набуває якісний контроль переміжних відмов, частка яких в усьому потоиі відмов становить приблизно 80-90\%, а також правильна ідентифікація стану циих каналів на основі аналізу сигналів помилок за мінімальний час їх відімкнення від рімення «корисних» задач. Розробка моделей $і$ алгоритмів аналізу послідовностей помилок, які є наслідком збоїв каналів КСКЗ з мажоритарним резервуванням, є основою програмування режиму ненавантаженого резервування. Це дасть можливість мінімізувати ймовірність недостовірної ідентифікації їхнього технічного стану. Досліджується надійність комп'ютерних систем критичного застосування, щзо використовують режим ненавантаженого резервування з точки зору стійкості до короткочасних збоїв, і визначаються області їх доцільного використання. Отримані у статті аналітичні вирази дають змогу робити вибір ненавантажених резервованих структур КСКЗ скорочень $і$ є основою відповідного програмного забезпечення.

Ключові слова: програмування, комп'ютерні системи критичного застосування, збій, ненавантажене резервування.

Вступ. Рівень надійності комп'ютерних систем критичного застосування (КСКЗ) залежить від інтенсивності відмов і збоїв їх елементів, досконалості засобів контролю, діагностування і рівня використаної надмірності. Забезпечення надійності КСКЗ, що не обслуговуються, в умовах обмежень на кількість резервованих каналів здійснюється шляхом використання спеціальних процедур ідентифікації збоїв при ненавантаженому резервуванні $[1,2]$. Ненавантажений резерв складається 3 одного чи декількох резервних елементів, які перебувають у ненавантаженому стані до початку виконання ними функцій основного елемента [3]. Такі резервні елементи перебувають у вимкненому стані і до моменту їх включення не є несправними.

Основними причинами виникнення помилок контролю $є$ недостовірна ідентифікація дієздатного стану. Особливого значення на сьогодні в роботі з підвищення ефективності використання каналів КСКЗ набуває якісний контроль переміжних відмов, частка яких в усьому потоці відмов становить приблизно 80-90\%, а також правильна ідентифікація стану цих каналів на основі аналізу сигналів помилок за мінімальний час їх відімкнення від рішення «корисних» задач. Програмування режиму ненавантаженого резервування забезпечується застосуванням відповідних методів та алгоритмів, що сприяють підвищенню ефективності використання каналів комп'ютерних систем критичного застосування.

Аналіз останніх досліджень та публікацій. Дослідженню комп'ютерних систем критичного застосування присвячено роботи ряду авторів. Так, у роботі [4] авторами досліджується синтез архітектури сучасної комп'ютерної системи для управління складним розподіленим об'єктом, основні етапи синтезу архітектури. Автори вказують на необхідність попереднього розкладання, структурування та формалізації системи, а також наведено основні етапи ієрархічної послідовності процесу розкладання. Автори роботи [5] пропонують комплекс, що включає кілька моделей та метод; він використовує зразки трафіку з декількох сеансів як вихідні дані для виконання короткочасного прогнозування трафіку. В роботах [6-8] автори акцентують свою увагу на методах розрахунку параметрів надійності та функціональної безпеки технічних систем, що 
характеризуються можливістю отримання строгих формульних виразів стаціонарних параметрів безпосередньо з графіка стану системи. В [7-13] відображаються результати досліджень моделей інформаційної структури системи підтримки, що враховує потужність транзакцій системи. Це оптимізує пропускну здатність вузлів і, як результат, підтримка ефективності системи електронного навчання зростає. В роботі [13] розглядається саме структура мережі гіперконвергентної базової мережі підтримки електронного навчання як основний фактор, що впливає на якість запитів системи. В роботі [14] розглянуто метод синтезу обернених операцій для відомих прямих операцій. Цей метод забезпечує побудову оберненої операції шляхом перетворення другого операнда дворозрядної двооперандної операції строгого стійкого криптографічного кодування.

Створенню методологічного забезпечення синтезу та аналізу наборів двооперандних двобітових криптографічних операцій з точною перестановкою присвячено роботу [16]. Автори провели дослідження, що грунтуються на результатах обчислювального експерименту, який полягає у синтезі двооперандних двобітових криптооперацій, які базуються на однооперандних, з подальшим пошуком пар операцій прямого та коректного зворотного криптоперетворення на основі повного пошуку. В процесі обчислювального експерименту автори отримали пари двооперандних операцій, що представлені кортежами чотирьох однооперандних операцій.

Таким чином, аналіз літератури [4-20] показав необхідність розробки універсального методу для КСКЗ у різних галузях, що дає можливість обрати один із режимів ненавантаженого резервування у комп'ютерних системах критичного застосування.

Мета дослідження - розробка моделей i алгоритмів аналізу послідовностей помилок, які $\epsilon$ наслідком збоїв каналів комп'ютерних систем критичного застосування 3 мажоритарним резервуванням, що дадуть змогу мінімізувати ймовірність недостовірної ідентифікації їхнього технічного стану та є основою відповідних програмних засобів.

Викладення основного матеріалу дослідження. Розробка програмного забезпечення для режиму ненавантаженого резервування забезпечує автоматизацію процесів у комп'ютерних системах критичного застосування. Важливими на початку перед проце- сом програмування $є$ дослідження та вибір відповідних моделей і розробка на їх основі відповідних алгоритмів. Моделювання оптимальної надійності представляє повний обсяг інформації та стратегій для визначення найбільш ефективних способів забезпечити відповідність систем усім необхідним вимогам до продуктивності, враховуючи графік, вартість та доцільність [19].

\section{1. Аналіз мажоритарної структури 3 ненавантаженим резервуванням}

Для аналізу алгоритмів і математичної моделі в роботі розглянуто дубльовану систему (ДС) 3 додатковим каналом, який знаходиться у ненавантаженому резерві (DCH), вмикається після відмови одного 3 каналів і починає втрачати надійність в момент виходу 3 ладу одного з працездатних каналів. Особливість цієї структури полягає в тому, що вона має три інформаційні блоки, схему порівняння i комутатор. Команду на перекомутацію каналів видає блок керування після аналізу сигналів зі схем порівняння, які контролюють всі три канали (рисунок 1).

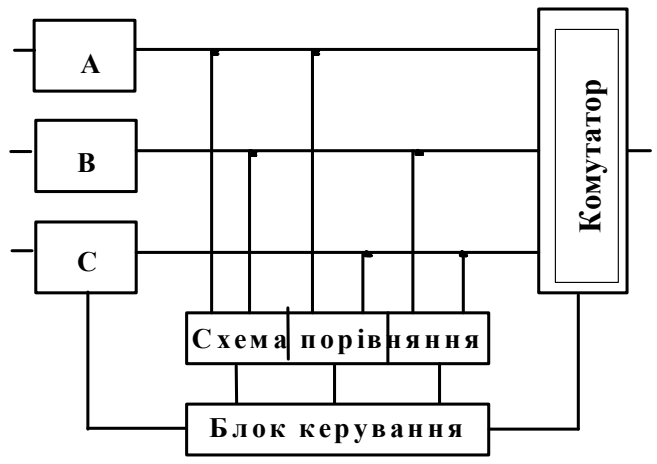

Рисунок 1 - Структурна схема DCH

При появі сигналу помилки в одному 3 каналів КСКЗ 3 ненавантаженим резервуванням ненавантажений канал вмикається, а відповідні технічні засоби здійснюють підрахунок сигналів помилок за інтервал спостереження ТС (заданий відрізок часу, підрахунок якого починається 3 появою першого сигналу помилки) i, якщо їхня кількість К більша заданої KZ, то контрольований канал ідентифікується як недієздатний і він вимикається від подальшого функціонування. Інтервалом безпеки ТВ будемо називати заданий відрізок часу, підрахунок якого починається з появою кожного сигналу помилки. Якщо $\mathrm{K}<\mathrm{KZ}$ i ТС > ТВ, контрольований канал КСКЗ вважається дієздатним і вмикається в роботу «за призначенням» 3 одночасним вимкненням одного 3 каналів у ненавантажений резерв після 
моменту кінця спостереження ТС. Якщо TC < TB, час спостереження збільшується на T = ТВ - ТС. Якщо за цей час не надійде сигнал помилки, канал вважається дієздатним. При появі сигналу помилки інтервал спостереження продовжується на величину ТВ. Якщо за час ТВ не надійде сигнал помилки, то канал вважається дієздатним. При появі L підряд сигналів помилок за час ТС контрольований канал ідентифікується як недієздатний і вимикається.

Конкретні величини ТC, TB, KZ, L повинні задаватися, виходячи 3 аналізу причин і викликаних ними послідовностей збоїв.

\section{2. Аналітична модель надійності DCH}

Розглянемо схему заміщення для системи, що працює при резервуванні заміщенням. 3 моменту вмикання системи в роботу спільно працюють два канали, у час $\tau$ виходу з ладу одного 3 них відбувається вмикання в роботу каналу C і комутація його на вихід системи. 3 часу $\tau$ починає витрачатися надійність каналу С. Оскільки у випадку збою одного з каналів системи за час ТС він ідентифікується і система вертається в попередній стан, то при достатньо тривалій експлуатації системи можна вважати, що до відмови система $\mathrm{K}$ разів вмикалася протягом часу ТС.
Нехай $\lambda Z$ - інтенсивність роботи одного каналу на збій, $\lambda \mathrm{B}$ - на сталу відмову, $\lambda=\lambda \mathrm{Z}+\lambda \mathrm{B}-$ інтенсивність роботи одного каналу на збій i відмову. Приймаємо: $\lambda \mathrm{B}=0,1 \lambda ; \lambda \mathrm{Z}=0,9 \lambda$. Тоді $\mathrm{TZ}-$ середній час напрацювання на збій двох каналів обчислюється за виразом

$$
T_{Z}=1 / 2 \cdot \lambda_{Z}
$$

Середня кількість збоїв двох каналів

$$
K=\mathrm{t} / \mathrm{T}_{\mathrm{Z}}=2 \lambda_{Z} \mathrm{tT}_{\mathrm{C}} .
$$

Згідно $з$ алгоритмом вмикання каналів після відмови двох із них відбувається перекомутація на резервний канал $C$, надійність якого почала витрачатися пізніше вхідних каналів:

$$
\begin{gathered}
P_{S S}(t)=P_{A B}(t)+P_{C}\left(t, t+2 \lambda_{C} T_{C} t\right)= \\
=e^{-0,2 \lambda t}+\int_{0}^{t} T_{C}\left(t-\left(\tau-2 \lambda_{C} T_{C} t\right)\right) f_{A B}(\tau) d \tau= \\
=e^{-0,2 \lambda t}+e^{-\lambda\left(t-\left(\tau+1,8 t T_{C} \lambda\right)\right)} .
\end{gathered}
$$

Частота відмов обчислюється за виразом (4). Отримані вирази підставляємо в (5).

3 урахуванням безвідмовності комутатора i схеми порівняння маємо вираз (6).

$$
\begin{gathered}
\mathrm{f}_{A B}(\tau)=\frac{\mathrm{dQ}_{A B}(\tau)}{\mathrm{d} \tau}=\mathrm{Q}_{A B}^{\prime}(\tau)=\left(1-e^{-0,2 \lambda \tau}\right)^{\prime}=0,2 \lambda \mathrm{e}^{-0,2 \lambda \tau} . \\
P_{C}(t, \tau)=\int_{0}^{t} e^{-\lambda\left(t-\left(\tau+1,8 T_{C} t \lambda\right)\right)} \cdot 0,2 \lambda e^{-0,2 \lambda \tau} d \tau=\frac{e^{1,8 \lambda^{2} T_{C} t}\left(e^{-0,2 \lambda t}-e^{-\lambda t}\right)}{4} . \\
P_{D C H}(t)=\left[e^{-0,2 \lambda t}+\frac{1}{4} e^{1,8 \lambda^{2} T_{C} t}\left(e^{-0,2 \lambda t}-e^{-\lambda t}\right)\right] P_{c p}(t) P_{K}(t) .
\end{gathered}
$$

\section{3. Марківська модель надійності DCH}

Знаючи інтенсивності відмов і відновлення окремих елементів системи, можна побудувати граф переходів, у якому вершинами будуть стани системи, ребрами - переходи з інтенсивностями відмов і відновлень. При побудові графа переходів (рисунок 2) приймаємо такі допущення:

1. В кожному зі станів $\mathrm{S}_{\mathrm{i}}$ водночас не може відбутися більше однієї відмови каналів.

2. Час спостереження $T_{H}$ настільки малий, що під час його не може відбутися збій інших каналів.

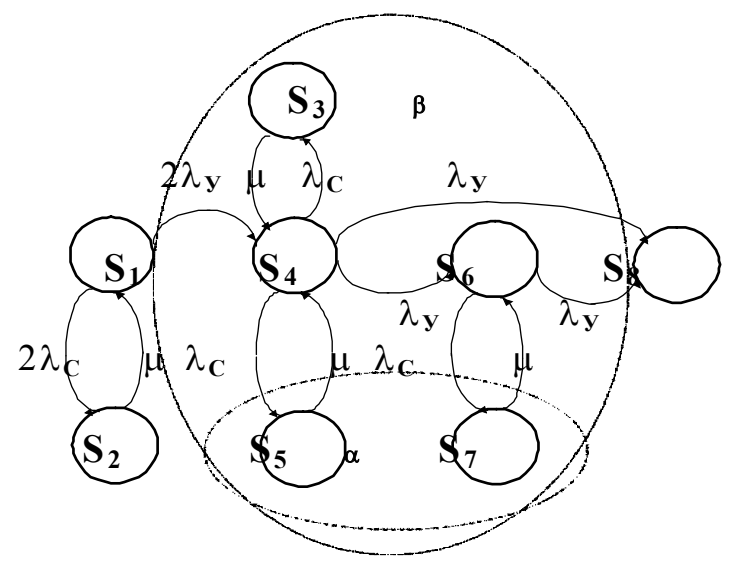

Рисунок 2 - Графи переходу станів DCH

(C) Т. О. Прокопенко, М. О. Можаєв, С. В. Рудницький, Ю. В. Рудницька, 2020 DOI: $10.24025 / 2306-4412.4 .2020 .221845$ 
Події S1 відповідає вхідний стан системи (два працездатні канали і один канал, який знаходиться в «холодному» резерві). Зі стану $\mathrm{S} 1$ система може перейти в стан S2 (збою одного 3 працездатних каналів) або в стан S4 (відмови одного 3 працездатних каналів). Зі стану S4 система може перейти в стан S3 (збою одного 3 працездатних каналів), водночас система залишиться в працездатному стані (оскільки алгоритм переключення каналів припускає перекомутацію на канал $\mathrm{C}$, який раніше знаходився в «холодному» резерві, у разі незбігу двох каналів, що залишалися), в стан S5 (збою каналу C), водночас система знаходиться в стані часткової відмови, S6 (відмови одного 3 працездатних каналів), водночас система залишається працездатною (канал C дієздатний) i S8 (відмови каналу C, що призводить до відмови системи). Аналогічно зі стану S6 система переходить в стан S7 (збою каналу $\mathrm{C}$, частковий збій системи, область $\alpha$ ) або стан S8 (відмови системи). Інтенсивності відновлення каналів після збою

$$
\mu=1 / T_{C} .
$$

На підставі побудованого графа переходів записуємо систему диференційних рівнянь Колмогорова:

$$
\left\{\begin{array}{l}
\frac{d P_{S 1}}{d t}=-\left(2 \lambda_{C}+2 \lambda_{Y}\right) P_{S 1}+\mu P_{S 2}, \\
\frac{d P_{S 2}}{d t}=-\mu P_{S 2}+2 \lambda_{C} P_{S 1}, \\
\frac{d P_{S 3}}{d t}=-\mu P_{S 3}+\lambda_{C} P_{S 4}, \\
\frac{d P_{S 4}}{d t}=-\left(2 \lambda_{C}+2 \lambda_{Y}\right) P_{S 4}+\mu P_{S 3}+\mu P_{S 5}+2 \lambda_{C} P_{S 1}, \\
\frac{d P_{S 5}}{d t}=-\mu P_{S 5}+\lambda_{C} P_{S 4} \\
\frac{d P_{S 6}}{d t}=-\left(\lambda_{C}+\lambda_{Y}\right) P_{S 6}+\mu P_{S 7}+\lambda_{y} P_{S 4}, \\
\frac{d P_{S 7}}{d t}=-\mu P_{S 7}+\lambda_{C} P_{S 6} \\
\frac{d P_{S 8}}{d t}=\lambda_{Y} P_{S 6}+\lambda_{Y} P_{S 4} .
\end{array}\right.
$$

Для врахування безвідмовності засобів порівняння і комутації введемо додаткові переходи зі станів S1, S4, S6 в стан S8, з інтенсивностями відмови комутатора і схем порівняння системи, що дорівнюють $\lambda_{\mathrm{Cп,K}}=0,05 \cdot \lambda_{\mathrm{B}}$.
Вирішуємо систему чисельним методом [17] і одержуємо всі ймовірності станів $\left\{P_{1-8}(t)\right\}$. Знаходимо функцію готовності системи (ФГ) як суми ймовірності станів, в яких система зберігає працездатність:

$$
P_{S S}(t)=P_{S 1}(t)+P_{S 2}(t)+P_{S 3}(t)+P_{S 4}(t)+P_{S 6}(t)(9)
$$

\section{4. Порівняльний аналіз моделей структури}

Для аналізу використаємо аналітичну модель DCH без урахування збоїв каналів, аналітичну модель DCH з урахуванням збоїв $\mathrm{DCH}_{\mathrm{CK}}$ i чисельну модель, отриману на основі марківських графів переходів. Аналітична модель DCH без урахування збоїв має вигляд

$$
\begin{gathered}
P_{2 D C H}(t)=e^{-2 \lambda t}+2 e^{-\lambda t}\left(1-e^{-\lambda t}\right)= \\
=P(t)(2-P(t)))=[P(t)(2-P(t))] P_{C C} P_{K}(t) .
\end{gathered}
$$

Для аналізу отриманих аналітичних виразів DCH зафіксуємо змінні $t, \lambda, \lambda_{\mathrm{Z}}, \lambda_{\mathrm{B}}, \lambda_{\mathrm{C \Pi}}$, $\lambda_{\mathrm{K}}$. Час $t$ будемо змінювати 30 до 3 років 3 кроком $\Delta t=2160$ годин. Інтенсивність відмов $\lambda$ каналів змінюється в межах $\lambda=10^{-5}-10^{-7} 1 /$ год. Для $\lambda_{3}, \lambda_{\mathrm{B}}, \lambda_{\text {Сп }}, \lambda_{\text {К вводимо }}$ залежність від $\lambda$, де $\lambda_{\mathrm{C \Pi}}=\mathrm{m} \lambda_{\mathrm{B}}, \lambda_{\mathrm{K}}=l \cdot \lambda_{\mathrm{B}}$; приймаємо $\mathrm{m}=2 * 10^{-2}, l=3 * 10^{-2}$. Підставляючи ці значення в отримані аналітичні вирази, аналізуємо аналітичні моделі $\mathrm{DCH}_{1} 3$ урахуванням збоїв, $\mathrm{DCH}_{2}$ без урахування збоїв i марківські моделі $\mathrm{DCH}_{1} 3$ урахуванням збоїв. Результати аналізу показали, що для $\lambda=10^{-5} 1 / \Gamma$ моделі $\mathrm{DCH}_{1}$ з урахуванням збоїв більш надійні, ніж $\mathrm{DCH}_{2}$ без урахування збоїв. Це зумовлено тим, що збій в одному з каналів $\mathrm{DCH}_{2}$ призведе до «втрати» каналу $\mathrm{i}$, як наслідок цього, до деградації системи. Результати, отримані при аналітичному і чисельному дослідженні моделей $\mathrm{DCH}_{1}$, незначно різнилися між собою, що підтверджує можливість використання цих моделей для оцінювання ненавантажених систем 3 різноманітними режимами вмикання каналів.

Висновки і перспективи подальшого розвитку. В результаті аналізу різних моделей DCH визначено області доцільного застосування залежно від різноманітних умов. При використанні каналів малої надійності $\lambda=10-5$ 1/год. при короткому часі функціонування системи спостерігається перевага $\mathrm{DCH}_{1}$ 3 урахуванням збоїв, порівняно $3 \mathrm{DCH}_{2}$ без урахування збоїв каналів системи. Для більш надійних каналів $\lambda=10-7$ 1/год. доцільно ви- 
користати $\mathrm{DCH}_{2}$ без урахування збоїв каналів. Аналітичні вирази для структур 3 «холодним» резервним каналом розглянуто більш глибоко в зв'язку з тим, що це найбільш прийнятний засіб підвищення надійності КСКЗ без обслуговування при тривалому періоді експлуатаціiі. Отримані аналітичні вирази дають можливість робити вибір ненавантажених резервованих структур КСКЗ.

Таким чином, запропоновано моделі та алгоритми, що забезпечують аналіз послідовностей помилок, які $є$ наслідком збоїв каналів комп'ютерних систем критичного застосування 3 мажоритарним резервуванням. Крім того, наводяться приклади моделей систем надійності, що дасть змогу мінімізувати ймовірність недостовірної ідентифікації їхнього технічного стану. Запропоновані моделі й алгоритми є основою відповідних програмних засобів.

\section{Список використаних джерел / References}

[1] M. Kuwaiti, N. Kyriakopoulos, and S. Hussein, "Network dependability, faulttolerance, reliability, security, survivability: A framework for comparative analysis", in 2006 Int. Conf. on Computer Engineering and Systems, IEEE Xplore, Cairo, Egypt, Febr. 26, 2007, INSPEC: 9232341. DOI: 10.1109/ICCES.2006.320462

[2] Alain Villemeur, Reliability, Availability, Maintainability and Assessment (Vol.1. Methods and Techniques). John Wiley\&Sons, 1992.

[3] Azianti Ismail, Won Jung, "Research trends in automotive functional safety", in 2013 Int. Conf. on Quality, Reliability, Risk, Maintenance, and Safety Engineering (QR2MSE), Chengdu, China, 2013, INSPEC: 13828750. DOI: 10.1109/QR2MSE.2013.6625523

[4] V. Mukhin, N. Kuchuk, N. Kosenko, H. Kuchuk, and V. Kosenko, "Decomposition method for synthesizing the computer system architecture", Advances in Intelligent Systems and Computing (AISC), vol.938, pp. 289-300, 2020.

DOI: 10.1007/978-3-030-16621-2_27

[5] G. Kuchuk, A. Kovalenko, I. E. Komari, A. Svyrydov, and V. Kharchenko, "Improving big data centers energy efficiency: traffic based model and method", in Green IT En- gineering: Social, Business and Industrial Applications. Studies in Systems, Decision and Control, V. Kharchenko, Y. Kondratenko, J. Kacprzyk, Eds., vol. 171, Springer, Cham, 2019. DOI: $10.1007 / 978-3-030-00253-4 \quad 8$

[6] V. Merlac, S. Smatkov, N. Kuchuk, and A. Nechausov, "Resourses distribution method of university e-learning on the hypercovergent platform", Conf. Proc. of 2018 IEEE $9^{\text {th }}$ Int. Conf. on Dependable Systems, Service and Technologies. DESSERT'2018, Kyiv, May 24-27, 2018, pp. 136-140.

DOI: 10.1109/DESSERT.2018.8409114

[7] N. Kuchuk, O. Mozhaiev, M. Mozhaiev, and H. Kuchuk, "Method for calculating of Rlearning traffic peakedness", in Proc. 2017 4th Int. Sci.-Pract. Conf. Problems of Infocommunications Science and Technology (PIC S and T), $\quad$ pp. 359-362, 2017. DOI: 10.1109/INFOCOMMST.2017.8246416

[8] I. B. Shubinsky, and A. M. Zamyshlyaev, "Topological semimarkov method for calculation of stationary parameters of reliability and functional safety of technical systems", Reliability: Theory \& Applications, SanDiego, USA, no. 2, 2012.

[9] D. Wilkie, "Pictorial representation of Kendall's rank correlation coefflclent", Teachmg Statistics, vol. 2, pp. 76-78, 1980.

[10] CENELEC EN 50126: Railway Applications - The Specification and Demonstration of Reliability, Availability, Maintainability and Safety (RAMS), 1998.

[11] H. Attar, M. R. Khosravi， S. I. Shmatkov, N. G. Kuchuk, and M. Alhihi, "Review and performance evaluation of FIFO, PQ, CQ, FQ, and WFQ algorithms in multimedia wireless sensor networks", International Journal of Distributed Sensor Networks, vol. 16 (6): 155014772091323, June, 2020. DOI: $10.1177 / 1550147720913233$

[12] Shivendra Singh, Varshita Gupta, Anuj Grover, and Kedar Janardhan Dhori, "Diagnostic circuit for latent fault detection in SRAM row decoder", in 21st Int. Symposium on Quality Electronic Design (ISQED), pp. 395-400, 2020.

DOI: 10.1109/ISQED48828.2020.9136968

[13] V. Donets, N. Kuchuk, and S. Shmatkov, "Development of software of e-learning in- 
formation system synthesis modeling process", Advanced Information Systems, vol. 2, no 2, pp. 117-121, 2018.

DOI: 10.20998/2522-9052.2018.2.20

[14] V. Rudnitsky, R. Berdybaev, R. Breus, N. Lada, and M. Pustovit, "Synthesis of reverse two-bit dual-operated strictly straight cryptographic coding on the basis of another operation", Advanced Information Systems, vol. 3, no 4, pp. 109-114, 2019. DOI: $10.20998 / 2522-9052.2019 .4 .16$

[15] A. Svyrydov, H. Kuchuk, and O. Tsiapa, "Improving efficiency of image recognition process: Approach and case study", in Proc. 2018 IEEE 9th Int. Conf. on Dependable Systems, Services and Technologies (DESSERT 2018), pp. 593-597.

DOI: 10.1109/DESSERT.2018.8409201.

[16] N. Lada, V. Dzyuba, R. Breus and S. Lada, "Synthesis of sets of non-symmetric twooperand two-bit crypto operations within the permutation accuracy", Technology audit and production reserves, vol. 2 , no. 2 (52), pp. 28-31, 2020.

DOI: 10.15587/2706-5448.2020.202099

[17] A. Kovalenko, and H. Kuchuk, "Methods for synthesis of informational and technical structures of critical application object's control system", Advanced Information Systems, vol. 2, no. 1, pp. 22-27, 2018.

DOI: 10.20998/2522-9052.2018.1.04

[18] S. Semenov, O. Sira, S. Gavrylenko, and N. Kuchuk, "Identification of the state of an object under conditions of fuzzy input data", Eastern-European Journal of Enterprise Technologies, vol. 1, no. 4 (97), pp. 22-30, 2019.

DOI: 10.15587/1729-4061.2019.157085

[19] W. Kuo, and Z. Ming, Optimal Reliability Modeling: Principles and Applications. Hoboken, NJ: John Whiley \& Sons, 2003.

[20] E. F. Moore, and C. E. Shannon, "Reliable circuits using less reliable relays - Part I", Journal of the Franklin Institute, vol. 262, no. 3, pp. 191-208, 1956.

T. O. Prokopenko ${ }^{1}$, D.Tech.Sc., professor,

M. O. Mozhaiev' ${ }^{2}$ Ph.D.,

S. V. Rudnytskyi ${ }^{1}$, Ph.D.,

Yu. V. Rudnytska ${ }^{1}$

${ }^{1}$ Cherkasy State Technological University

Shevchenko blvd, 460, Cherkasy, 18006, Ukraine

${ }^{2}$ National Scientific Center «Hon. Prof. M. S. Bokarius Forensic Science Institute», Zolochivska St., 8a, Kharkiv, Ukraine

\section{PROGRAMMING OF UNLOADED REDUNDANCY MODE IN COMPUTER SYSTEMS OF CRITICAL APPLICATION}

Today, the quality control of intermittent failures, the share of which in the total failure rate is approximately 80-90\%, as well as the correct identification of the state of these channels based on the analysis of error signals for the minimum time of their disconnection from the solution of "useful" tasks are of particular importance today in improving the efficiency of using channels of computer systems of critical application. The purpose of the study is to develop models and algorithms for analyzing the sequences of errors that result from channel failures of computer systems for critical use with majority redundancy, which will minimize the likelihood of inaccurate identification of their technical condition and are the basis of appropriate software. In the paper for analyzing the algorithms and mathematical model a duplicated system with an additional channel, which is situated in the unloaded reserve, turns on after the fault with one of the channels and begins to lose reliability at the fault-time with one of the working channels, has been considered. Knowing the intensities of failures and recoveries of the system's individual elements, a transition graph is constructed in which the vertices will be the states of the system, the edges will be the transitions with intensities of failures and recoveries. As a result of analyzing various DCH models the areas of expedient application depending

(C) Т. О. Прокопенко, М. О. Можаєв, С. В. Рудницький, Ю. В. Рудницька, 2020 DOI: $10.24025 / 2306-4412.4 .2020 .221845$ 
on various conditions have been determined. When using low-reliability channels, an advantage of $\mathrm{DCH}_{1}$ with a short-time system operation, taking into account failures, is observed compared to $\mathrm{DCH}_{2}$ without taking into account failures of the system channels. For more reliable channels, it is advisable to use $\mathrm{DCH}_{2}$ without taking into account channel failures. Analytical expressions for the structures with a "cold" backup channel are considered in more depth due to the fact that this is the most acceptable means of increasing the CSCA reliability without maintenance for a long operation's period. The reliability of computer systems of critical application, which use the mode of unloaded redundancy, is researched in terms of resistance to short-term failures, and the areas of their appropriate use are determined. The analytical expressions obtained in the article allow to make a choice of unloaded redundant structures of CSCA.

Keywords: software, computer systems of critical application; failure; unloaded redundancy.

Стаття надійила 28.11.2020

Прийнято 18.12.2020

(C) Т. О. Прокопенко, М. О. Можаєв, С. В. Рудницький, Ю. В. Рудницька, 2020 DOI: $10.24025 / 2306-4412.4 .2020 .221845$ 